\title{
Revisitação à orgânica conceptual trabalhada por António Damásio em O Livro da Consciência com aplicação ao comportamento humano em artes performativas $^{1}$
}

\author{
ANABELA MENDES
}

We know that the relationship between body and brain is established by neurons and their extensions: axons and dendrites. We also know that the complexity of our behaviour is due to this main system of the mind's functioning. The possibility of looking at the relationship between the structure of the brain and that of the mind and the rest of the body has not always been taken for granted. "Neurons refer to the body", says Damásio. The emotional manifestations of each of us and the ability to plan and organize tasks coexist in the same brain space, although their actions and effects occur in different areas of the brain mass and, therefore, also maintain a relationship inside this spaciality as a functional difference. The above findings are thus as valid for those who produce artistic performances as for anyone who expects this activity. What does the performer (actor /actress) think and feel while waiting for the performance to begin? What exactly will those who wait for the very beginning of that exact action feel and expect? Do they feel awaited as well? How does one combine and articulate the memory of the creation and construction of a performance? Where can their fears and rejoicing fit, precisely those emotions the other party does not experience in the same way?

INTERACTION BODY-BRAIN / MIND / PERFORMER / SPECTATOR / CARTOGRAPHY CABINET

1. Sabemos que a relação entre corpo e cérebro é estabelecida pelos neurónios e suas extensões: os axónios e os dendritos. Sabemos também que a complexificação dos nossos comportamentos se deve a este sistema principal de funcionamento da mente. A possibilidade de encararmos

1 Este ensaio dá sequência a um outro texto anterior: «Notas para uma Sociologia das Artes do Espectáculo: Reflexão sobre a utilização de parâmetros cognitivos aplicados a públicos de teatro e outras artes», publicado no n. ${ }^{\circ} 17$ da primeira série da revista Sinais de Cena (Junho de 2012, pp. 60-79), no qual a autora arriscou as primeiras ideias sobre o estudo humanístico da neurociência. 
o relacionamento entre a estrutura do cérebro e a da mente e o restante corpo nem sempre foi um dado adquirido.

As manifestações emotivas de cada um de nós e a capacidade de planificar e organizar tarefas convivem num mesmo espaço cerebral, ainda que a sua acção e o seu efeito ocorram em zonas distintas da massa do cérebro e, por isso, mantenham entre si também uma relação de diferença funcional espaço-operativa. Isto não impede que consideremos como verdadeira a afirmação de Damásio de que «os neurónios referem-se ao corpo» (Damásio, 2010: 69-70).

A constatação do acima exposto torna-se assim tão válida para quem desenvolve actividade performativa artística como para quem especta essa actividade. À partida, ambos os intervenientes (quem representa/ /apresenta e quem assiste à representação/apresentação) possuem as mesmas características orgânicas gerais e podem desenvolvê-las plenamente, tanto no âmbito da experiência artística como em qualquer outra situação de vida quotidiana. No entanto, os que espectam dependem do início da intenção, estimulação e acção de quem executa o acto performativo. Esta dependência, justificada pela lógica do próprio processo artístico em questão (início e prossecução do espectáculo até ao seu final), transforma um plano de igualdade das partes em relação ao funcionamento entre corpo e cérebro numa sucessiva hierarquização de acções em que uma parte depende obviamente da outra.

Acresce dizer que a convencionalidade da relação entre quem representa/apresenta e quem observa se baseia também na existência de tempos próprios, durante os quais os espectadores manifestam individual e colectivamente, com maior efusividade ou não, os efeitos neles causados pelo espectáculo. Essas manifestações contemplam em regra um leque visível e audível relativamente restrito de expressão de movimento facial e corporal que se traduz no bater de palmas, aplauso vocal, assobio, apupo, pateada, lágrimas, suspiros, sorrisos e gargalhadas que em geral acontecem no fim de cada espectáculo, embora possam surgir em momentos de elevada qualidade artística ou de comoção, menos quando o espectáculo não corresponde às expectativas aguardadas.

Esta é a matriz geral de comportamento que herdámos da cultura ocidental, reforçada ao longo do século XVIII, a partir do momento em que as salas de espectáculos se foram reconfigurando para receberem espectadores sentados num espaço de plateia, onde antes eles se amontoavam de pé. 
2. Só se começa a ser espectador no momento em que o espectáculo se inicia e, mesmo assim, nem sempre a consecutividade do processo espaçotemporal tem em todo o espectador o mesmo impacto. Um pontapé de partida pode desencadear um ilimitado conjunto de reacções. Esta dependência, cuja lógica todos compreendemos e aceitamos, condiciona de forma natural a relação entre quem representa/apresenta e quem assiste.

Os processos mentais, sobretudo do foro emocional dos potenciais espectadores, antes do início do espectáculo, geram-se segundo o mapeamento que o cérebro de cada um vai fazendo, seleccionando e montando o que deverá acompanhar o horizonte de expectativa, a prevalência do gosto estético, a interacção da memória, o significado cultural do objecto artístico escolhido, o estado corporal na ocasião, fenómenos como o cansaço ou a ausência dele, o estar em grupo ou só. De como funciona este mapeamento, não temos qualquer consciência.

Este mapeamento é uma realidade que outros estudam por nós e em nós. Mesmo que entre espectadores de arte performativa esteja um neurocirurgião, um neuroinvestigador, um especialista em mapeamento cerebral, nenhum deles se comportará enquanto espectador de modo distinto de nós. Acresce dizer, porém, que o objecto de investigação destes particulares espectadores não começou historicamente por ser o cérebro, um qualquer cérebro, mas o cérebro doente. $\mathrm{E}$ o cérebro doente talvez não possua a disponibilidade para se concentrar na fruição e recepção de um espectáculo, seja ele de que natureza for.

$\mathrm{O}$ que da investigação destes espectadores especializados aproveita a todos - um melhor e mais profundo conhecimento do cérebro - não nos faculta, apesar de tudo, a olho nu e em tempo real, o acesso ao gabinete $d a$ cartografia (expressão afectiva para a acção do cérebro). Aquilo de que nos consciencializamos é, por exemplo, de um movimento de cruzar ou descruzar de pernas quando estamos sentados no lugar que corresponde ao nosso bilhete para o espectáculo e que resulta da acção do cérebro mapeador que esteve entretido a criar «informação para si próprio» (Damásio, 2010: 90). Mas mesmo este movimento automatizado acontece normalmente ao mesmo tempo que estamos a fixar o olhar no cenário, se este estiver à vista, a observar outros espectadores que vão entrando na sala em busca dos seus assentos e que captam a nossa atenção pelo modo como se apresentam, ou pelo tom de voz com que dialogam uns com os outros.

Se por momentos tínhamos tido consciência, ou talvez não, de que as nossas pernas procuravam conforto no espaço, depois de nos termos 
concentrado numa série sequencial de acções observadas, e em que participámos como organismo vivo e completo, era agora possível acontecer, por mera casualidade, que o nosso olhar encontrasse na sala alguém conhecido que também nos reconhecia. Nessa circunstância, todo o processo de observação e contemplação anteriores que resultara de um número para nós indeterminado de mapas e imagens executados dentro do nosso cérebro potenciaria uma «interacção» decorrente do cruzamento de olhares a culminar no mútuo reconhecimento entre duas pessoas - nós como sujeito e aquele outro sujeito que identificámos e que nos identificou.

Desta vez, o gabinete da cartografia teria estado em actividade ao produzir mapas e imagens que contextualizavam acções (todas as anteriores ao reconhecimento da presença no teatro de alguém de quem nos lembrávamos e que parecia lembrar-se de nós), acrescidas agora de novos mapeamentos que nos devolviam informação anteriormente armazenada como memória e cujos padrões recuperávamos no estabelecimento de contacto visual com esse alguém. A três dimensões e como realidade apreendida momentaneamente, era-nos mostrado aquilo que neurónios e ínfimos circuitos, a actividade de sinapses e de «imagens perceptuais em vários domínios sensoriais» nos tinham devolvido como presentificação operada de «certo modo» e «algures» enquanto aguardávamos o início do espectáculo (Damásio, 2010: 167-9).

A descrição desta experiência individual, que poderia ser a de qualquer um de nós, multiplicar-se-á indefinidamente e em variantes próprias no que respeita ao comportamento de grande parte dos espectadores presentes numa sala de espectáculos antes do início da função.

3. Enquanto aparentemente nada acontece ainda em cena, muita coisa está a acontecer no espaço preparado para nos receber. Todos nós, os espectadores, estamos a criar e a servir-nos de memória, a interagir através dela, mantendo em moldes aceitáveis e em gestão saudável o nosso corpo e o nosso cérebro. Se estivermos muito embriagados ou com uma valente pedrada de sono, faremos parte de um ínfimo grupo de espectadores que ali se encontram corporalmente, mas cujos cérebro e mente são alvo de disfuncionalidade pontual para o que ali vai acontecer.

Por seu turno, quem representa/apresenta, e apesar de ser responsável por dar o primeiro passo, abrindo assim o espectáculo, é justamente nessa condição que aceita o compromisso de vir a ser sujeito em interacção, através de um processo de construção de presença, expressão, 
movimento e relacionamento consigo próprio e com outros, tarefas essas que são produto de actividade cerebral e corporal similares às dos espectadores. Aos actores, porém, aguarda-os um exercício de mostração para o qual se prepararam com brio e afinco. Nisso, distinguem-se dos espectadores. Apesar da diferenciação de propósitos e acções entre actores e espectadores, justifica-se que se saliente a existência de uma identidade de espécie que caracteriza o comum funcionamento corporal e mental tanto nuns como noutros.

Assim, poderemos afirmar com Damásio que actores e espectadores partilham uma matriz comum no funcionamento cerebral:

Quando os neurónios «disparam», a corrente eléctrica conhecida como potencial de acção propaga-se a partir do corpo celular e ao longo do axónio. O processo é muito rápido, demorando apenas alguns milissegundos, o que dará uma ideia das escalas temporais extraordinariamente diferentes entre processos cerebrais e mentais. Precisamos de centenas de milissegundos para nos tornarmos conscientes de um padrão que seja apresentado aos nossos olhos. Vivemos os sentimentos numa escala de segundos, ou seja, milhares de milissegundos, e de minutos. (Damásio, 2010: 369-70)

Provavelmente, esse mapeamento e a correspondente criação de imagens, que se desenrolam a uma velocidade completamente inacessível à nossa consciência, produzem em cada um dos indivíduos presentes na sala o mesmo tipo de fenómenos e actividade mental. Apesar disso, são distintos os planos sequenciais da acção performativa da participação daqueles que se organizam para a acção de espectar. Sendo ambos, em si, processos de representação estrutural de tudo o que se encontra dentro e fora do cérebro e que o activa, estruturam igualmente o corpo próprio, mas também tudo o resto que nos afirma como seres individuais e colectivos.

Será que nos podemos questionar sobre se os mapas e imagens que estabelecem os contornos do funcionamento do cérebro de um performer/actor evidenciam a mesma estimulação que ocorre no cérebro de cada espectador? Em relação aos fenómenos neurais, poderemos inferir de forma positiva que a actividade química e eléctrica será a mesma. Deste pressuposto, teríamos de excluir os espectadores embriagados e ensonados que exemplificaram (ponto 2) características de disfuncionalidade episódica. 
Porém, o que pensará e sentirá o performer/actor enquanto espera pelo início do espectáculo? Em que medida os que o aguardam se sentirão aguardados por ele? Como conjuga e articula ele a memória de criação e construção do espectáculo? Onde cabem os seus medos de que não sofre a outra parte? (Damásio, 2010: 89-90; 92-5)

4. Recordo-me de um exercício que executei em diversas alturas como pré-preparação para a construção de uma personagem e que tinha a função de me fornecer, e aos outros actores presentes naquela oficina na Covilhã, maior consciencialização do corpo, da mente e da realidade circundante. As indicações de Konrad Zschiedrich, o professor e encenador alemão com quem trabalhávamos no início da década de 1980, pediam aos formandos que seguissem com o maior pormenor possível todas as acções que realizassem desde que se levantavam até se deitarem.

O que acontecia quando faziam a barba, como se processava a escolha da roupa para vestir nesse dia, em que talher pegavam primeiro antes de começarem a comer, quantos goles de água ou de vinho bebiam quando tinham sede? Que pé punham primeiro à frente quando começavam a andar, o que fixavam com o olhar quando observavam alguém ou alguma coisa?

A experiência com este exercício de auto-análise e consciencialização de acções que executamos todos os dias sem que delas nos apercebamos deveria no fim de cada dia ser descrita como acontecera.

Os resultados foram catastróficos, e a maior parte dos protagonistas desistiu ao fim das primeiras horas. Ninguém parecia suportar o excesso de consciência, sobretudo quanto a acções e situações que tinham automatizado ao longo dos anos. No entanto, o exercício sempre me pareceu fabuloso, porque criava em nós uma autodisciplina e um autodomínio a que não estávamos habituados, ensinava-nos a estabelecer uma outra relação com o espaço e com o tempo, treinava a nossa capacidade de observação, fazia-nos aprender processos de selecção, ajudava-nos a dar atenção àquilo que normalmente não consideramos importante. Através deste exercício, nós poderíamos transformar-nos, ou pelo menos adquirirmos uma nova consciência essencial para um actor.

A rejeição manifestada pela maior parte dos formandos pareceu-me que tinha que ver com resistência mais mental do que corporal ao exercício. Ao princípio, todos achavam engraçada a ideia de seguir com pormenor acções do quotidiano que deveriam relatar posteriormente. 
Aconteceu até em alguns casos, naqueles que levaram mais a sério o exercício, que a dificuldade surgia quando tinham de contar o que acontecera. Mais do que descrever as acções e as situações em que tinham estado envolvidos, os actores ocupavam-se em exprimir o que para eles resultava em sofrimento e mal-estar por terem de mudar os seus hábitos comportamentais sem alcançarem claramente os objectivos a que se tinham proposto.

Na altura, ninguém pensava ainda na relação corpo-cérebro como hoje já o podemos fazer. O exercício proposto então por Konrad Zschiedrich tinha inúmeras vantagens aplicáveis à construção de qualquer espectáculo, mas era principalmente um exercício que procurava desconstruir hábitos e rotinas, tornando o cérebro mais plástico e dinâmico e, por consequência, a totalidade do corpo do actor.

A resistência oferecida pelos participantes nesta experiência à inovação e à transformação tem de ser entendida à luz do próprio funcionamento do cérebro humano.

Em primeiro lugar, «[o] cérebro que se preocupa com o corpo é, na verdade, um prisioneiro do corpo e das suas informações» (Damásio, 2010: 155). Nessa medida, a resistência verificada justifica-se porque, independentemente da infinidade de padrões que se estejam sempre a criar no nosso cérebro, é preciso que haja um tempo de ajuste entre o que era e o que está para ser. Fazer a barba a pensar no filme que se viu ontem ou no passeio à beira-mar que se vai dar hoje é muito diferente de dirigir exclusivamente a atenção para um processo que consiste em: molhar o rosto para pôr a mousse ou o gel, reparar na quantidade de produto que se vai espalhar, espalhar o produto, confirmar se a lâmina está em condições, começar a fazer a barba, verificar que não escapam pêlos, seguir o movimento das mãos e dos braços enquanto a barba é feita, enxaguar o rosto depois de feita a barba, secá-lo um pouco e pôr aftershave ou água-de-colónia no fim. Quantos golpes faciais terão acontecido desta vez? Em primeiro lugar, o tempo de execução, o tempo de observação e o tempo de captação desta sequência de acções triplica ou quadruplica em relação ao tempo normal de fazer a barba, e não se tem o prazer ou a preocupação de ao mesmo tempo ir pensando em outras coisas.

Em segundo lugar, «os cérebros inteligentes são profundamente preguiçosos. Sempre que possível fazem menos em vez de mais, uma filosofia minimalista que seguem religiosamente» (Damásio, 2010: 156). Assim sendo, podemos melhor compreender a reacção dos jovens actores ao exercício pedido. 
O exemplo do exercício aqui narrado, que é também minimalista, não só pelas razões que Damásio invoca mas também pela natureza de execução do próprio exercício, pode ajudar-nos a entender e a sentir que as preocupações do actor antes do início do espectáculo são basicamente incoincidentes com as do espectador. Ambos mantêm um nível e uma intensidade de expectativa em relação ao espectáculo, mas o facto de cada um desempenhar um papel distinto na função justifica que o funcionamento do cérebro, sendo idêntico e selectivo nos dois, produza resultados diferentes. A haver trocas comportamentais específicas entre cena e sala, isso poderá verificar-se se entre os espectadores houver actores. Nesse caso, a experiência e o conhecimento estimulados na memória destes particulares espectadores antecipará uma relação simpática com o que vier a acontecer em cena.

Se bem que seja importante que o espectador tenha consciência do seu corpo no espaço, enquanto assiste a um espectáculo, essa consciência será muito mais aguda em quem se expõe física, emocional e mentalmente, como é o caso dos actores durante a representação ou apresentação de uma performance. Esta diferenciação de grau de exposição não invalida que ambas as partes reajam, em termos gerais, biológica e neuronalmente do mesmo modo.

5. Os estudos em neurociência têm vindo a tornar-se cada vez mais próximos de todos aqueles que encontram, nesta área específica do conhecimento, interesse e curiosidade intelectual. Quem não sente vontade de se conhecer melhor? Quem não deseja perceber com mais profundidade os comportamentos dos outros? Quantas vezes nos desentendemos e conflituamos uns com os outros sem nos darmos o tempo mental e físico necessário para nos apercebermos de que esses estados de corpo e de espírito, melhor dizendo, de mente, nos convocam como um todo e têm a sua origem e arquitectura no gabinete da cartografia de cada um de nós? Desentendimentos e conflitos acontecem muitas vezes porque a nossa ignorância - um ponto de partida que nem sempre se transforma em ponto de chegada verdadeiro - e a nossa distracção em relação a nós e aos outros são superiores ao sentido de tolerância emocional e à compreensão que poderíamos desencadear, activar e manter em relação aos outros. Se formos capazes de intuir que os estados mentais podem equivaler aos estados e comportamentos físicos, estaremos em consonância com o que Damásio nos diz: 
A perspectiva pessoal deve ser usada e desfrutada em relação àquilo que nos transmite directamente: experiência que pode ser tornada consciente e que pode ajudar-nos a orientar a vida, desde que uma extensa análise reflexiva ulterior - o que inclui o escrutínio científico - valide o seu parecer. (Damásio, 2010: 384)

Não basta que protejamos a cabeça com um capacete num gesto automático quando andamos de mota, apesar de essa protecção poder minimizar estragos e até salvar-nos a vida em situação de acidente. É fundamental que saibamos o que estamos a proteger. E o que estamos a proteger é um lugar a que não temos acesso directo e que, apesar disso, nos mantém vivos.

Enquanto metemos com cuidado os cabelos dentro do capacete para que eles e o vento não impeçam a nossa visão da estrada, dentro do nosso cérebro essas acções estão a ser mapeadas, criando uma correlação entre mente e cérebro e obviamente com o todo orgânico, ao mesmo tempo que a consciência desta sequência de acções, se a houver, não despertará provavelmente em nós qualquer reflexão mais elaborada sobre vida e morte. Se antes tivermos tido um acidente de mota, talvez a memória dele nos ocorra uma vez ou outra, mas o mais certo é tendermos a relativizar essa experiência mesmo que o resultado dela seja termos ficado vivos.

Quem se dedica às artes do espectáculo saberá melhor do que ninguém como é sensível este território de relacionamento e entendimento emocional, como são problemáticas e complexas as ligações entre os seus protagonistas. Não me refiro apenas a quem se expõe mais, os actores, mas também a quem se mantém oculto nos bastidores, na escuridão da mesa de régie, entre agulhas e linhas na confecção de um figurino. Todos sem excepção contribuem para a exequibilidade de uma ideia, de um projecto, que se consuma em acto artístico e que será dado a ver a outros.

Arte em presença e como acontecimento em tempo real configura uma infinita sucessão de mapeamentos e criação de imagens no cérebro/ /mente, extensíveis ao corpo de cada um, correlacionáveis entre si, e nesta particular circunstância tendo em conta as correspondentes versões cartográficas que os gabinetes de outros estão a produzir ao mesmo tempo com uma finalidade comum.

Todos os intervenientes sabem que a construção do espectáculo se apoia no cometimento individual e colectivo, independentemente da especificidade colaborativa e das expectativas desencadeadas ao longo do processo em curso. É um bem inestimável que tomemos consciência 
de que esta realidade se produz pela competência, se encontra inexoravelmente ligada à criatividade e ao poder inventivo, é apoiada por várias técnicas inerentes às diferentes artes em jogo, se socorre de capacidades e meios tecnológicos cuja função consiste em melhor fazer desabrochar o que a cena mostra.

Em todo este processo, estão activas regiões cerebrais, nem sempre as mesmas e nem sempre ao mesmo tempo, de um determinado número de colaboradores a quem são atribuídas e pedidas tarefas específicas, em nome das quais se desencadeiam em permanência mapeamentos e acontecimentos mentais que, por exemplo, invocam a memória autobiográfica, ajudam a antecipar o futuro, conduzem à formulação de juízos morais (Damásio, 2010: 283-4).

Mas, se é verdade que tudo isto acontece dentro do nosso cérebro/ /mente, os resultados desse trabalho «privado» e «resguardado» dão origem a percepções, sensações, sentimentos, gestos, movimentos, tonalidades vocais que se manifestam na nossa massa corpórea, que passa assim a ser permeável ao nosso comportamento.

O que nos está oculto e que Damásio estima como sendo «possivelmente [d]os fenómenos mais complexos da natureza» (2010: 384-5) não se nos oferece à contemplação nem temos capacidade para o avaliar a olho nu. A única coisa que podemos fazer é observar os mapeamentos e imagens cerebrais, feitos através de aparelhos manipulados por técnicos e cientistas com preparação e formação adequadas. Também com estes actores, podemos partilhar o que eles nos quiserem dar a conhecer numa linguagem que possamos compreender e à qual queiramos dar interpretação.

Talvez devamos aceitar com humildade e maravilhamento que a Natureza, ao dar-nos um cérebro, uma mente e um corpo, enformando-os como os conhecemos e vivenciamos, o fez em nome da preservação da nossa espécie independentemente das evoluções a que ela esteja sujeita, tal como acontece com a maioria das espécies animais vertebradas.

6. Quando Hamlet suspende entre mãos o crânio de Yorick (V, 1), o bobo da corte lembrado como companheiro de jogos e brincadeiras de infância do príncipe, fá-lo para se referir aos efeitos da morte sobre o corpo. O que ele, porém, segura com as mãos, e ao mesmo tempo, é ainda uma invocação de vida. E essa invocação, que é feita no calor emocional de agarrar o que sempre estivera oculto em vida e cuja interioridade lhe era uma incógnita, abre-se agora como espaço de correspondências, ao articular distintas temporalidades num mesmo espaço. Aquele crânio específico 
torna-se um objecto que, tendo preservado vida, volta momentaneamente à sua funcionalidade no memorável discurso de Hamlet.

A rememoração autobiográfica do príncipe da Dinamarca acontece como o reavivar de um tempo passado referenciado como feliz. O crânio que o primeiro Clown/coveiro diz ter pertencido a Yorick, devolvendo-lhe assim identidade, não passa de um oco invólucro. Esse objecto transporta simultaneamente vida e morte. Já não possui massa encefálica, já não mantém em actividade neurónios nem células, nem constrói padrões de referência que façam activar o organismo. Apesar disso, é criada pela interpretação do actor, qualquer actor, que fez ou venha a fazer de Hamlet, uma ineludível correspondência entre esse objecto esvaziado de vida interina, tão simbólico e premonitório, e as físicas e mentais mãos do próprio Hamlet. Movimento, suspensão dele, voz e expressão facial darão conta do que não se vê e não se apalpa. Em boa verdade, sem a estimulação do crânio vazio, não teria existido aquele momento tão singular na personagem de Hamlet. Bendito Shakespeare!

No fecho desta deambulação damasiana sobre corpo-cérebro, ocorreu-me referir um curto vídeo que vi recentemente. Trata-se de uma pequena parcela de um espectáculo maior do coreógrafo grego Dimitris Papaioannou. ${ }^{2}$ A obra de Papaioannou chama-se Nowhere e foi realizada em 2009 para inaugurar o palco principal renovado do Teatro Nacional em Atenas. A acompanhar os 3 min $46 \mathrm{~s}$ visíveis no YouTube, há a indicação de que a referida coreografia nasceu em lembrança de Pina Bausch. Cheguei a Nowhere pela mão do bailarino e coreógrafo Mário Afonso. Posteriormente descobri outros pequenos vídeos feitos a partir da obra do coreógrafo grego, que enunciam e mostram a constante conflitualidade das relações humanas através de narrativas mitológicas e da história da Grécia (Medea e coreografia para os Jogos Olímpicos de 2004), mas também em episódios quotidianos que se ocupam da fragilidade dos comportamentos e da precariedade das relações. ${ }^{3}$

Dimitris Papaioannou parece ser um homem com grande poder de observação, sensível, culto e de um extremo rigor nas suas composições.

2 Disponível em http://vimeo.com/100021239.

3 Cf. http://vimeo.com/100021239; https://www.youtube.com/watch?v=pWRIn2iDwDs; https:// www.youtube.com/watch?v=Yj9cuCEfZeY 
O bailarino e coreógrafo demonstra possuir uma enorme capacidade inventiva que aplica na criação de imagens e no movimento detalhado que as suporta. $O$ corpo é fragmento e totalidade, recorrendo-se muitas vezes à focalização no inesperado pormenor e, a partir dele, na progressão de um desenho colectivo apoiado na organização de pares e grupos, como acontece em Nowhere.

O que nos é dado ver nesta coreografia, nos tais 3 min $46 \mathrm{~s}$, tem um efeito surpreendente que resulta de uma imaginação poderosa e de uma meticulosidade respirada à flor da pele. Cada bailarino vale primeiramente pelo seu braço e pela sua mão, as partes com maior visibilidade de todo um corpo, que alternam em sequência à esquerda è̀ direita de cena, a que se pode juntar o rosto iluminado e no qual nada parece mexer-se porque ele reflecte apenas e tão-só concentração. Cada bailarino é parte e todo de um movimento que ondula e se desenha a si próprio. A corrente de braços e mãos, sob poderosa luz, organizada no espaço como um contínuo ininterrupto, fonte de aturada aprendizagem, permite que recortemos em abstracto as partes de cada corpo em acção e que referenciam o lado direito e o lado esquerdo da própria cena. A confluência de ambos projecta-se sobre o par que constitui em termos visuais o ponto de fuga e ao mesmo tempo o ponto de chegada da dinâmica de movimento. Eis um bom exemplo de demonstração do exercício simultâneo e coordenado do individual e do colectivo. Eis um bom exemplo de articulação e correspondência entre cérebro e corpo sem que nos tenhamos de ocupar do que vai sendo desenhado, gravado e desgravado no interior do cérebro de cada um daqueles bailarinos (Damásio, 2010:386).

A nós, ter-nos-ia interessado a fruição do espectáculo. Através do pequeno vídeo, só poderemos muito vagamente imaginar o que foi Nowhere e talvez não consigamos também ter um grande alcance sobre aquilo que terá fundamentado a lembrança a Pina Bausch. Desejamos encontrar através desta, apesar de tudo, poderosa sequência de imagens a ligação que nos conduz à interpretação. Se estivermos condicionados por um determinado assunto, enquanto vemos a sequência de Nowhere, como é o caso do nexo corpo-cérebro, muitas das ligações que viermos a estabelecer se centrarão na possibilidade de podermos demonstrar aquele que foi o nosso ponto de partida e como lhe poderemos dar resposta. Mas o nosso imaginário (cérebro/mente-corpo) possui uma plasticidade muito maior e uma capacidade de estabelecer interacção para lá daquilo que conscientemente somos capazes de incorporar durante a visualização. Cada um de nós saberá como reagir perante outras 
possibilidades relacionadas com experiências e vivências próprias. É neste plano que se apresentam as diferenças entre cada um de nós, entre os caminhos específicos de cada um de nós.

Haverá aqueles que serão particularmente sensíveis à evolução do movimento do par em cena e ao que acontece a esses bailarinos no contexto da coreografia. Outros haverá que se concentrarão na mostração e acção das ligações entre braços e mãos, uma espécie de coralidade da dança, sem dúvida, o novo, o inesperado.

Todos chegaremos ao fim dos 3 min $46 \mathrm{~s}$ já diferentes do que éramos antes de termos visto um pedaço de Nowhere. A circuitação das nossas células em todo o nosso ser terá registo dessa experiência, do que sobre ela pensámos, daquilo que nos emocionou e do que vier a ser.

REFERÊNCIAS BIBLIOGRÁFICAS

DAmásıo, António (2010), O Livro da Consciência : A construção do cérebro consciente, Lisboa, Temas e Debates / Círculo de Leitores.

\section{ANABELA MENDES}

Anabela Mendes (1951) é professora na Faculdade de Letras da Universidade de Lisboa e investigadora sénior do Centro de Estudos de Comunicação e Cultura da Universidade Católica Portuguesa. Desenvolve a sua actividade profissional e ensaística nas áreas seguintes: Literatura de Expressão Alemã, Cultura Alemã, Estética e Filosofia da Arte, Literatura de Viagens, Ciência e Arte, Modernidade e Vanguardas, Teoria e Estética do Teatro, Sociologia das Artes do Espectáculo, Estudos sobre o Espectador de Artes Performativas, e Teoria e Dramaturgia Radiofónica. Desenvolve actualmente um projecto dedicado a teatro e tribunal. 